\title{
Demographic, lifestyle, and reproductive determinants of serum anti-Müllerian hormone levels in adult women of reproductive age in Ilorin, North-Central Nigeria
}

\author{
Oyinkansola Islamiyat Lawal ${ }^{1 *}$ (i) and Jameelu-deen Omokunmi Yusuff ${ }^{2}$ (D)
}

\begin{abstract}
Background: Anti-Müllerian hormone is a dimeric glycoprotein produced by the granulosa cells of preantral and small antral follicles of the ovaries. It is a reliable biomarker of ovarian reserve, ageing, and response in the management of women with infertility. However, there are few studies on the determinants of serum anti-Müllerian hormone in Nigerian women. This study aimed to investigate determinants of serum anti-Müllerian hormone among adult women of reproductive age. The study was a hospital-based cross-sectional study involving 161 women of reproductive age attending the gynaecology clinic and immunisation clinic of a Nigerian tertiary hospital. Baseline characteristics were collected using a semi-structured questionnaire. Serum anti-Müllerian hormone was quantified using enzyme-linked immunosorbent assay.

Results: In univariate analysis, age $(B=-0.035, P=0.000)$, parity $(B=-0.080, P=0.001)$, and infertility duration $(B=-$ $0.050, P=0.011)$ had a negative relationship with serum anti-Müllerian hormone, while ethnicity $(B=0.180, P=0.040)$, body mass index $(B=0.015, P=0.010)$, and cycle length $(B=0.042, P=0.000)$ had a positive relationship with serum anti-Müllerian hormone. In multivariable analysis, all relationships except infertility duration persisted.

Conclusion: We found that age, ethnicity, parity, infertility duration, body mass index, and cycle length were associated with serum anti-Müllerian hormone. A large prospective population-based study is required to better understand factors that are associated with serum anti-Müllerian hormone in an ethnically diverse country like Nigeria.
\end{abstract}

Keywords: Anti-Müllerian hormone, Ovarian reserve, Infertility, Reproductive-age women, Determinants

\section{Background}

Anti-Müllerian hormone (AMH) is a dimeric glycoprotein produced by the ovarian granulosa cells of preantral and early antral follicles measuring up to $8 \mathrm{~mm}$ in diameter $[1,2]$. It is highly sensitive to age-related changes in ovarian reserve with minimal inter- or intracycle variability $[3,4]$. It is a predictor of ovarian response

\footnotetext{
* Correspondence: islamiyatlawal2013@gmail.com

'Pan African University, Life and Earth Science Institute (including Health and Agriculture) (PAULESI), University of Ibadan, Ibadan, Oyo State, Nigeria Full list of author information is available at the end of the article
}

and ovarian hyperstimulation syndrome in controlled ovarian hyperstimulation [5, 6]. Serum AMH level correlates strongly with day-3 antral follicular count (AFC) when compared with other biomarkers of ovarian reserve [7]. This has led to a significant increase in the clinical use of $\mathrm{AMH}$ as a biomarker of ovarian reserve [8].

Researchers have demonstrated that some lifestyle and reproductive factors influence serum levels of AMH in women of reproductive age [9-11]. Lifestyle choices such as smoking and binge drinking have been linked to lower levels of serum AMH in premenopausal women

\section{Springer Open}

(0) The Author(s). 2021 Open Access This article is licensed under a Creative Commons Attribution 4.0 International License, which permits use, sharing, adaptation, distribution and reproduction in any medium or format, as long as you give appropriate credit to the original author(s) and the source, provide a link to the Creative Commons licence, and indicate if changes were made. The images or other third party material in this article are included in the article's Creative Commons licence, unless indicated otherwise in a credit line to the material. If material is not included in the article's Creative Commons licence and your intended use is not permitted by statutory regulation or exceeds the permitted use, you will need to obtain permission directly from the copyright holder. To view a copy of this licence, visit http://creativecommons.org/licenses/by/4.0/. 
$[9,12]$. Studies have also reported inconsistent findings on the relationship between body mass index and serum $\mathrm{AMH}$; therefore, it remains unclear if $\mathrm{BMI}$ is an independent predictor of serum AMH in women $[9,13,14]$. Furthermore, reproductive factors such as age at menarche and parity have been shown to predict serum AMH, with conflicting findings reported in different studies [9-11]. Also, ethnic and racial variations in serum anti-Müllerian hormone have been reported in previous studies, which suggest that varied lifestyle and genetic and environmental factors may contribute to variations in serum AMH in women [15-17].

Therefore, with the increasing clinical application of serum anti-Müllerian hormone in assisted reproduction across Africa including Nigeria, more studies are needed to understand factors that affect this biomarker in this population with the hope of improving the interpretation of this biomarker in this population. This study determined demographic, reproductive and lifestyle factors associated with serum anti-Müllerian hormone levels in adult women of reproductive age attending the University of Ilorin Teaching Hospital, North-Central Nigeria. We hypothesised that selected, demographic, reproductive, and lifestyle factors will be significantly associated with serum AMH in adult women of reproductive age.

\section{Methods}

\section{Study design and participants}

The study was a hospital-based cross-sectional study conducted at a Nigerian tertiary hospital between March and July 2019. The study aimed to determine predictors of serum AMH levels in women of reproductive age. Data from women who had completed the study questionnaire on demographics, lifestyle, and reproductive characteristics were consecutively retrieved and considered for this study.

Participants were adult women of reproductive age between 18 and 45 years with a menstrual cycle length of 21 to 35 days attending the gynaecology and immunisation clinic of a Nigerian tertiary hospital. The study excluded women who had used hormonal contraceptives or medications 3 months before presentation, women with a history of thyroid disorders, women with diabetes mellitus, women with a current or past history of use of chemotherapy and/or radiotherapy, and those who had a history of pelvic surgery (uterine or ovarian).

Data from women who met the eligibility criteria alone were purposively used to minimise selection bias. Data from 196 women who met the eligibility criteria were available; women with incomplete data were subsequently excluded from the analysis. A total of 161 women had complete information on demographic, reproductive, and lifestyle factors relevant to the study and had results of serum AMH analysis.

\section{Ethical consideration}

Ethical approval was gotten from the University of Ilorin institutional ethics review committee (ERC/PAN/2019/ 01/1869) and informed consent was signed by each participant before participation.

\section{Data collection}

We retrieved baseline information from the patients and clinical records using a semi-structured questionnaire. All women with missing or incomplete data were excluded from the study. We collected 3-5 $\mathrm{ml}$ of random peripheral venous blood from each study participant via venepuncture after obtaining informed consent. Whole blood was left at room temperature for an hour for clot retraction and then centrifuged at $5000 \mathrm{rpm}$ for about 10-15 min to separate the serum. Clear serum was carefully pipetted into sterile plain sample bottles and stored at $-20{ }^{\circ} \mathrm{C}$ until analysis.

Serum samples were analysed using a double-antibody human AMH enzyme-linked immunosorbent assay (ELISA) following the manufacturer's manual (Calbiotech Inc., El Cajon, CA, USA 2018) at the Chemical Pathology Research Laboratory of the University of Ilorin Teaching hospital. The sensitivity of the test was $0.039 \mathrm{ng} / \mathrm{ml}$.

\section{Statistical analysis}

Data were analysed using SPSS version 25 for Windows (IBM Corp., Armonk, NY, USA, version 25.0). Independent variables were demographic, reproductive, and lifestyle characteristics, while the dependent variable was serum AMH. Participants with missing data were excluded from the analysis. Variables were summarised using frequency and proportions for categorical data and median (interquartile range (IQR)) or mean \pm standard deviation for the continuous variables that were not normally distributed or normally distributed, respectively. Relationships were explored using linear regression analysis at both univariate and multivariable levels. Serum AMH levels were $\log _{10}$ transformed to ensure compliance with the requirements for linear regression analysis. The level of significance was set at $5 \%$. Factors that were found to be significant on univariate analysis were subsequently fit into a multivariable analysis to adjust for the effects of covariates.

\section{Sample size determination}

The minimum sample size for multiple linear regression for 11 independent variables was determined using an online calculator (A- priori sample size) [18]. Assuming an anticipated effect size of 0.15 , level of significance at 0.05 , and $90 \%$ power, the minimum sample size required was determined to be 152 . A total of 161 women were recruited for this study. 


\section{Results}

Baseline characteristics

Table 1 summarises the baseline demographic, lifestyle, and reproductive characteristics of the study population using descriptive statistics. Categorical data were summarised in frequencies and proportions and continuous data were summarised in mean (standard deviation) or median (interquartile range) depending on normality distribution.

Participants' age ranged from 21 to 40 years with the majority 70 (43.2\%) having normal BMI $(18.5-<25 \mathrm{~kg} /$ $\mathrm{m}^{2}$ ). The majority of the women do not consume alcoholic beverages $(88.2 \%)$ and none of them were current smokers. Of those that consumed alcoholic beverages, the distribution of alcoholic drinks was reported as $52.6 \%$ alcoholic herbal concoctions, beer, and wine, and more than one type of alcoholic beverage had a distribution of $15.8 \%$ each. However, the majority were infrequent drinkers with $83.3 \%$ consuming alcoholic beverages once in a while and others rarely (16.7\%).

Of those who consumed caffeine-containing beverages; $88.1 \%$ consumed Coca-Cola, $4.6 \%$ consumed coffee, $0.9 \%$ green tea, and $6.4 \%$ reported consuming more than one type of caffeinated drink. The distribution of women by frequency of caffeine consumption was $8 \%$ rarely, $54.5 \%$ once in a while, $7.1 \%$ once in a month, $9.8 \%$ weekly, $8 \%$ more than once weekly, $10.7 \%$ daily, and $1.8 \%$ more than once daily.

The average age at menarche was 15 years, with the majority having a regular menstrual cycle $(87 \%)$ with an average cycle length of 28 days. Close to half of the women have a history of infertility (44.7\%), with a median infertility duration of 4 years.

\section{Linear regression analysis}

Univariate linear regression models were analysed for each study variable (Table 2). All study variables that were significant on univariate analysis (Table 2) at a 5\% level of significance (except infertility duration) were subsequently fitted into a multivariable linear regression model (Table 3). In univariate analysis, age, ethnicity, body mass index, cycle length, parity, and infertility duration were significant. Age $(B=-0.035, P=0.000)$, parity $(B=-0.080, P=0.001)$, and infertility duration ( $B=-0.050, P=0.011)$, showed a negative relationship with serum $\mathrm{AMH}$, while $\mathrm{BMI}(B=0.015, P=0.010)$, cycle length $(B=0.042, P=0.000)$, and ethnicity (Yoruba) ( $B=0.180 ; P=0.040)$ had a positive relationship.

In the univariate regression analysis of statistically significant factors in women less than 35 years and those greater than 35 years independently, age; $<35$ years $(B=$ - 0.021, $P=0.025)$ and $\geq 35$ years $(B=-0.131, P=$ $0.000)$ and parity; $<35$ years $(B=-0.065, P=0.017)$ and $\geq 35$ years $(B=-0.085, P=0.029)$ were statistically
Table 1 Baseline characteristics

\begin{tabular}{|c|c|}
\hline \multicolumn{2}{|l|}{ Demographic characteristics } \\
\hline Variables & Median (IQR)/n (\%) \\
\hline Age (years) & $30(7)$ \\
\hline \multicolumn{2}{|l|}{ Ethnicity } \\
\hline Yoruba & $141(87.6)$ \\
\hline Igbo & $6(3.7)$ \\
\hline Hausa & $1(0.6)$ \\
\hline Others & $13(8.1)$ \\
\hline \multicolumn{2}{|l|}{ Lifestyle characteristics } \\
\hline Body mass index $\left(\mathrm{kg} / \mathrm{m}^{2}\right)$ & $25(7.33)$ \\
\hline \multicolumn{2}{|l|}{ Alcohol intake } \\
\hline No & $142(88.2)$ \\
\hline Yes & $19(11.8)$ \\
\hline \multicolumn{2}{|l|}{ Caffeine intake } \\
\hline No & 49 (30.4) \\
\hline Yes & $112(69.6)$ \\
\hline \multicolumn{2}{|l|}{ Past smoking } \\
\hline No & $160(99.4)$ \\
\hline Yes & $1(0.6)$ \\
\hline \multicolumn{2}{|l|}{ Current smoking } \\
\hline No & $161(100)$ \\
\hline Yes & $0(0)$ \\
\hline \multicolumn{2}{|l|}{ Passive smoking } \\
\hline No & $145(90.1)$ \\
\hline Yes & $16(9.9)$ \\
\hline \multicolumn{2}{|l|}{ Reproductive characteristics } \\
\hline Age at menarche (years) & $15(2)$ \\
\hline Cycle length (days) & $28(3)$ \\
\hline \multicolumn{2}{|l|}{ Cycle regularity } \\
\hline No & $21(13.0)$ \\
\hline Yes & $140(87.0)$ \\
\hline \multicolumn{2}{|l|}{ Dysmenorrhoea } \\
\hline No & $85(52.8)$ \\
\hline Yes & $76(47.2)$ \\
\hline \multicolumn{2}{|c|}{ Past hormonal contraceptive use } \\
\hline No & $147(91.3)$ \\
\hline Yes & $14(8.7)$ \\
\hline Parity & $1(2)$ \\
\hline \multicolumn{2}{|l|}{ History of infertility } \\
\hline No & $89(55.3)$ \\
\hline Yes & $72(44.7)$ \\
\hline Duration of infertility (years) & $4(3)$ \\
\hline
\end{tabular}

significant in both groups. However, the rate of decrease of $\mathrm{AMH}$ with age in women 35 years and older was 6 times the rate of decrease in women less than 35 years. 
Table 2 Univariate linear regression analysis

\begin{tabular}{llll}
\hline Model: Log $_{10}$ AMH $(\mathbf{n g} / \mathrm{ml})$ & & & \\
\hline & Standard error & $\boldsymbol{B}$ & $\boldsymbol{P}$ value \\
\hline Age (years) & 0.006 & -0.035 & $0.000^{*}$ \\
Ethnicity (Yoruba) & 0.087 & 0.180 & $0.040^{*}$ \\
Lifestyle factors & & & \\
$\quad$ BMl (kg/m ${ }^{2}$ ) & 0.006 & 0.015 & $0.010^{*}$ \\
Alcohol intake & 0.090 & 0.060 & 0.509 \\
Caffeine intake & 0.063 & 0.039 & 0.541 \\
Passive smoking & 0.097 & -0.156 & 0.109 \\
Reproductive factors & & & \\
Age at menarche & 0.016 & -0.011 & 0.490 \\
Cycle length (days) & 0.011 & 0.042 & $0.000^{*}$ \\
Regular cycles & 0.086 & -0.166 & 0.054 \\
Dysmenorrhoea & 0.058 & 0.012 & 0.843 \\
Past hormonal contraceptive use & 0.104 & 0.029 & 0.781 \\
Parity & 0.023 & -0.080 & $0.001^{*}$ \\
History of infertility & 0.059 & -0.024 & 0.677 \\
Duration of infertility (years) & 0.019 & -0.050 & $0.011^{*}$ \\
\hline
\end{tabular}

*Significance at $5 \%$ level of significance

Cycle length $(B=0.037, P=0.003)$, BMI $(B=0.014, P=$ $0.016)$, and ethnicity (Yoruba) $(B=0.237, P=0.008)$ were significant in women less than 35 years only. Adjusting for covariates in multivariable analysis all variables' influence remained significant (Table 3)

\section{Discussion}

Overall, of all the factors analysed in this study, age, ethnicity, BMI, cycle length, and parity had a significant relationship with serum AMH despite adjusting for the influence of all significant factors.

\section{Demographic factors}

We found that with a unit increase in age there was a $3.5 \%$ reduction in serum AMH level. This is similar to findings from previous studies which suggests that serum AMH levels reduce with age and hence is a reliable marker of ovarian ageing $[19,20]$. However, on multivariable analysis, there was a reduction in

Table 3 Multivariable linear regression analysis

\begin{tabular}{llll}
\hline Log $_{10} \mathbf{A M H}(\mathbf{n g} / \mathbf{m l}), \boldsymbol{R}^{\mathbf{2}=33.6 \%}$ & Std. error & $\boldsymbol{B}$ & $\boldsymbol{P}$ value \\
\hline Constant & 0.362 & 0.358 & 0.325 \\
Age (years) & 0.006 & -0.031 & $0.000^{*}$ \\
Ethnicity (Yoruba) & 0.073 & 0.155 & $0.037^{*}$ \\
Cycle length (days) & 0.010 & 0.036 & $0.000^{*}$ \\
Parity & 0.020 & -0.053 & $0.009^{*}$ \\
Body mass index $\left(\mathrm{Kg} / \mathrm{m}^{2}\right)$ & 0.005 & 0.014 & $0.003^{*}$ \\
\hline
\end{tabular}

*Significance at $5 \%$ level of significance percentage reduction in serum AMH by age by $0.4 \%$. Women 35 years and older had a rate of decrease in serum AMH with age that was 6 times the rate of decrease noted in those less than 35 years.

Yoruba women in this study were found to have a $15.5 \%$ higher serum AMH level than women of other ethnic groups. This is similar to findings from previous studies that demonstrated a significant ethnic and racial variation in serum AMH levels in women in the same population $[15,16]$. This could be due to some lifestyle and genetic variations among these ethnic groups [17]. However, given the lack of adequate representation of the major ethnic groups in this study, a population study of a larger sample size, with better representation of the different ethnic groups will give a better understanding of the influence of ethnicity on serum AMH in an ethnically diverse population like Nigeria.

\section{Lifestyle factors}

All women recruited in this study were non-smokers (active). However, about $9.9 \%$ of the study population reported exposure to second-hand smoking. There was no significant association between passive smoking and serum AMH. This is in line with the findings by Plante et al. and further lends credence to their conclusion that the influence of smoking on the ovarian reserve is most likely from a direct influence that is gotten from active and current smoking [21]. However, given the small proportion of participants exposed to passive smoking, a larger study with a larger proportion of second-hand smokers will better depict the extent of the impact this has on ovarian reserve.

There was no association found between alcohol intake and serum AMH level, similar to what was found in previous studies $[9,22]$. Although this was contrary to findings by Bressler et al., who found a 26\% lower AMH in binge drinkers among African-American women [10]. This contradiction is likely because the majority of women who reported alcohol consumption in our study are social drinkers and reported infrequent alcohol intake. Therefore, the effect of alcohol on AMH is likely quantity dependent.

There was no significant relationship between caffeine intake and serum AMH. This finding is in line with the study done by Kinney et al. where no association was found between caffeine consumption and AFC, FSH, estradiol, and inhibin [22]. However, it is important to note that our study did not make a more objective quantification of the amount of caffeine consumed in these women. An objective measure of the quantity of caffeine consumed by each woman will be a better predictor of the influence of caffeine on serum AMH levels.

However, we found a positive relationship between $\mathrm{BMI}$ and serum $\mathrm{AMH}$, with an increase in BMI, leading 
to a corresponding increase in serum AMH levels. After adjusting for age, ethnic group, cycle length, and parity, a unit increase in BMI resulted in a $1.4 \%$ increase in serum AMH. This contradicts the findings by previous studies in southwest Nigeria, in which researchers found no significant relationship between BMI and serum $\mathrm{AMH}[14,23]$. Freeman et al. found a negative relationship in women of late reproductive age outside Nigeria [13]. The discrepancies between these findings are likely due to the inclusion of women with polycystic ovary syndrome (PCOS) in this study, which is often associated with high BMI and high serum AMH [24]. Also on sub-analysis by age group, BMI remained significant in women less than 35 years only.

\section{Reproductive factors}

There was no association demonstrated between age at menarche and serum AMH in this study, which is in line with findings from the study by Dólleman et al. [9]. However, Bragg et al. reported that independent of age, smoking, and body mass index; women with early age at menarche had significantly higher AMH as young adults [10], whereas another study found that infertile women with early age at menarche were at a significantly higher risk of diminished ovarian reserve in the long-term [11]. The contradiction between these studies and ours is most likely due to the difference in population, as the initial study focused more on young adult women as opposed to women within the entire reproductive age, whereas the latter was done in infertile women only.

There was a significant positive relationship between cycle length in days and serum AMH in the study population. An increase in cycle length by a day was associated with a $3.6 \%$ increase in serum AMH independent of age, ethnicity, BMI, and parity. This is most likely due to the inclusion of women with PCOS in the study group. Anovulatory women with PCOS have relatively longer cycle lengths with relatively high random serum AMH levels [24]. However on sub-analysis, by age group, this relationship was not statistically significant in women 35 years of age and older.

Cycle regularity was not associated with serum AMH, contradicting findings by Dólleman et al. where cycle irregularity was associated with a significantly less serum AMH level [9]. This finding is unexpected as irregular menstrual cycles are usually found in women with PCOS in whom it is associated with high serum AMH or older women with menopause-related irregularities who are more likely to have low levels of AMH. Women in this study who reported irregular menstrual cycle had an average age of 30 years; therefore, cycle irregularity was likely, not due to menopause-related irregularity.

However, the experience of dysmenorrhea was not associated with serum AMH levels in this population. This is contrary to a previous study in which women with severe dysmenorrhoea had significantly lower serum AMH levels [25]. Their findings could be linked to endometriosis which some studies have suggested could significantly decrease serum AMH and can also present with severe dysmenorrhea [26]. The lack of association in our study could be due to the lack of accountability for the severity of dysmenorrhea experienced by women in this study. Also, from clinical records, none of the women recruited was diagnosed with endometriosis.

Furthermore, there was a negative relationship between parity and serum AMH with an increase in parity being associated with a $5.3 \%$ decrease in serum AMH after adjusting for age, ethnicity, BMI, and cycle length. This contradicts the findings by Dólleman and colleagues who found an increase in age-specific AMH was associated with an increase in parity [9]. However, similar findings were reported by Bragg et al. who found that women with 2 and 3 or more parous experiences had significantly lower serum AMH levels when compared with nulliparous women [10]. However, when the analysis was adjusted for age, the negative relationship persisted in multivariable regression and sub-analysis of women younger than 35 years and women 35 years and older. Also, given that women who were currently on contraceptives were excluded in this study, this effect is likely not due to the higher likelihood of contraceptive use by women with higher parity.

Having a history of infertility did not have a significant relationship with serum AMH levels in this study. This is similar to findings by Hvidman et al. who reported no difference in AMH and antral follicular count in fertile and infertile women of similar age groups [27]. This is not unexpected as various factors are responsible for infertility in women, outside of their intrinsic ovarian reserve. However, there was a significant negative relationship between the duration of infertility and serum AMH, which implies that with an increase in the duration of infertility in years, there is a corresponding reduction in serum AMH levels. This is contrary to findings by Oke et al. in Southwest Nigeria, in which authors reported no statistically significance [23]. Our finding is likely due to the influence of age on serum AMH, as older women are more likely to have experienced infertility for a longer period. This is evidenced by the loss of statistical significance after adjusting for age in regression analysis.

Lastly, past hormonal contraceptive use was not associated with serum AMH levels in this study. Although various studies have reported a decrease in $\mathrm{AMH}$ with the use of hormonal contraception, this suggests that past use of hormonal contraceptives does not permanently affect ovarian reserve [28-30]. This is similar to findings by Van den Berg et al. who found a 23\% increase in serum AMH after discontinuation of oral contraceptive pills [31]. 


\section{Strengths and limitations}

The strength of this study is in its evaluation of 11 independent variables and their association with serum $\mathrm{AMH}$ in the same sample of Nigerian women in a clinical setting, where the results are most applicable.

Although the sample size was statistically adequate for the objectives of this study, a large, prospective population-based study is essential to better study the demographic, lifestyle, and reproductive factors that are associated with serum AMH as a marker of ovarian reserve and functioning. The relative homogeneity in terms of ethnicity and the hospital-based nature of this study makes it deficient in determining the true extent to which these factors influence AMH in a culturally and ethnically diverse population like Nigeria.

Also, the study did not measure objectively the amount of alcohol and coffee intake and did not document the severity of dysmenorrhea in the women in this study. This could contribute to the lack of association demonstrated; therefore, future research should aim to objectively qualify and quantify these factors to arrive at a better conclusion.

Furthermore, endometriosis could not be appropriately ruled out as laparoscopy and histology are not routinely done in women who had presented with infertility, although clinical history and records revealed no history suggestive of endometriosis in women in this study.

\section{Conclusion}

Our findings suggest that age, ethnicity, BMI, parity, and cycle length independently determined the serum AMH levels in premenopausal women. This will add to already available evidence on AMH in Nigeria and further improve the interpretation of this hormone in clinical settings. More research is needed to further elucidate the factors that may determine serum AMH levels in this population as a means to further understand ovarian function in this population.

\section{Abbreviations}

AFC: Antral follicular count; AMH: Anti-Müllerian hormone; BMI: Body mass index; ELISA: Enzyme-linked immunosorbent assay; IQR: Interquartile range; PCOS: Polycystic ovary syndrome

\section{Acknowledgements}

We express our sincere gratitude to the Pan African University, an initiative of the African Union Commission, for the provision of funds for running this research. We also appreciate Dr S.A. Biliaminu, Consultant Chemical Pathologist, University of Ilorin Teaching Hospital, for his contribution towards the hormonal analysis for this study.

\section{Authors' contributions}

Ol was involved in study conception and design, literature search, data collection, input and analysis, laboratory analysis, manuscript drafting, and review. JO was involved in data collection, laboratory analysis, manuscript draft, and review. Both authors read and approved the manuscript.

\section{Funding}

The research funds from the Pan African University Scholarship (African Union) were used to procure reagents and materials, logistics, and employ personnel for the research from which this paper emanates.

\section{Availability of data and materials}

Data supporting findings are available from the corresponding author on reasonable request.

\section{Declarations}

Ethics approval and consent to participate

This was gotten from the University of Ilorin Teaching Hospital institutional ethics review committee (ERC/PAN/2019/01/1869). All participants signed informed consent before recruitment in the first study.

Consent for publication

Not applicable

Competing interests

The authors declare that they have no competing interests.

\section{Author details}

${ }^{1}$ Pan African University, Life and Earth Science Institute (including Health and Agriculture) (PAULESI), University of Ibadan, Ibadan, Oyo State, Nigeria.

${ }^{2}$ Department of Chemical Pathology and Immunology, University of Ilorin

Teaching Hospital, Ilorin, Kwara State P.M.B 1459, Nigeria.

Received: 25 November 2020 Accepted: 20 July 2021

Published online: 11 August 2021

\section{References}

1. Bhide P, Shah A, Gudi A, Homburg R (2012) The role of anti-Müllerian hormone as a predictor of ovarian function. The Obstetrician \& Gynaecologist 14:161-166. https://doi.org/10.1111/j.1744-4667.2012.00112.x

2. Jeppesen JV, Anderson RA, Kelsey TW, Christiansen SL, Kristensen SG, Jayaprakasan K et al (2013) Which follicles make the most anti-Müllerian hormone in humans ? Evidence for an abrupt decline in AMH production at the time of follicle selection. Mol Hum Reprod 19:519-527. https://doi.org/1 0.1093/molehr/gat024

3. La Marca A, Grisendi V, Griesinger G (2013) How much does AMH really vary in normal women? Int J Endocrinol 2013:959487. https://doi.org/10.1155/2 $013 / 959487$

4. Iwase A, Nakamura T, Osuka S, Takikawa S, Goto M, Kikkawa F (2016) AntiMüllerian hormone as a marker of ovarian reserve: what have we learned, and what should we know? Reprod Med Biol 15:127-136. https://doi.org/1 0.1007/s12522-015-0227-3

5. Broer SL, Dólleman M, Opmeer BC, Fauser BC, Mol BW, Broekmans FJM (2011) AMH and AFC as predictors of excessive response in controlled ovarian hyperstimulation: a meta-analysis. Hum Reprod Update 17:46-54. https://doi.org/10.1093/humupd/dmq034

6. Broer SL, Dolleman M, Van Disseldorp J, Broeze KA, Opmeer BC, Bossuyt PMM et al (2013) Prediction of an excessive response in in-vitro fertilization from patient characteristics and ovarian reserve tests and comparison in subgroups : an individual patient data. Fertil Steril 100:420-429. https://doi. org/10.1016/j.fertnstert.2013.04.024.e7

7. Fanchin R, Schonauer LM, Righini C, Guilbourdenche J, Frydman R, Taieb J (2003) Serum anti-Müllerian hormone is more strongly related to ovarian follicular status than serum inhibin B, estradiol, FSH and LH on day 3. Hum Reprod 18:323-327

8. Jamil Z, Fatima SS, Ahmed K, Malik R (2016) Anti-Mullerian hormone: above and beyond conventional ovarian reserve markers. Dis Markers 2016: 5246217 https://doi.org/10.1155/2016/5246217

9. Dólleman M, Verschuren WMM, Eijkemans MJC, Dolle MET, Jansen EHJM, Broekmans FJM et al (2013) Reproductive and lifestyle determinants of antiMüllerian hormone in a large population-based. J Clin Endocrinol Metab 98: 2106-2115. https://doi.org/10.1210/jc.2012-3995

10. Bragg JM, Kuzawa CW, Agustin SS, Banerjee MN, Mcdade TW (2012) Age at menarche and parity are independently associated with Anti-Müllerian hormone, a marker of ovarian reserve, in Filipino young adult women. Am J Hum Biol 24:739-745. https://doi.org/10.1002/ajhb.22309 
11. Weghofer A, Kim A, Barad DH, Gleicher N (2013) Age at menarche : a predictor of diminished ovarian function ? Fertil Steril 100:1039-1043 https://doi.org/10.1016/j.fertnstert.2013.05.042

12. Hawkins Bressler L, Bernardi LA, De Chavez PJ, Baird DD, Carnethon MR, Marsh EE (2017) Alcohol, cigarette smoking, and ovarian reserve in reproductive- age African-American women. Am J Obstet Gynecol 215:1-20. https://doi.org/10.1016/j.ajog.2016.07.012

13. Moy V, Jindal S, Lieman H, Buyuk E (2015) Obesity adversely affects serum anti-Müllerian hormone (AMH) levels in Caucasian women. J Assist Reprod Genet 32:1305-1311. https://doi.org/10.1007/s10815-015-0538-7

14. Okunola T, Olusegun Ajenifuja K, Morebise Loto O, Salawu A, Omitinde SO (2017) Follicle stimulating hormone and anti-Müllerian hormone among fertile and infertile women in Ile-Ife, Nigeria : is there a difference? Int J Fertil Steril 11:33-39

15. Bleil ME, Gregorich SE, Adler NE, Sternfeld B, Rosen MP, Cedars MI (2014) Race/ethnic disparities in reproductive age: an examination of ovarian reserve estimates across four race/ethnic groups of healthy, regularly cycling women. Fertil Steril 101:199-207. https://doi.org/10.1016/j.fertnstert.2 013.09.015

16. Bhide P, Gudi A, Shah A, Homburg R (2015) Serum anti-Mullerian hormone levels across different ethnic groups: a cross-sectional study. BJOG 122: 1625-1629. https://doi.org/10.1111/1471-0528.13103

17. Tal R, Seifer DB (2013) Potential mechanisms for racial and ethnic differences in antimüllerian hormone and ovarian reserve. Int J Endocrinol 2013:818912. https://doi.org/10.1155/2013/818912

18. Soper, D.S. (2020) A-priori sample size calculator for multiple regression [Software]. Available from http://www.danielsoper.com/statcalc

19. Wiweko B, Prawesti DM, Hestiantoro A, Sumapraja K, Natadisastra M, Baziad A (2013) Chronological age vs biological age: an age-related normogram for antral follicle count, FSH and anti-Mullerian hormone. J Assist Reprod Genet 30:1563-1567. https://doi.org/10.1007/s10815013-0083-1

20. Okunola OT, Ajenifuja OK, Loto MO, Salawu A, Omitinde OS, Akande J, Oke E (2016) Age-specific nomograms for follicle stimulating hormone and antiMullerian hormone: a pilot study in Ile-Ife, Nigeria. Int J Reprod BioMed (Yazd) 14:777-782

21. Plante BJ, Cooper GS, Baird DD, Steiner AZ (2010) The impact of smoking on antimüllerian hormone levels in women aged 38 to 50 years. Menopause 17:571-576

22. Kline J, Tang A, Levin B (2016) Smoking, alcohol and caffeine in relation to two hormonal indicators of ovarian age during the reproductive years. Maturitas. 92:115-122. https://doi.org/10.1093/humrep/del496

23. Oke EO, Oke OF, Salawu AA, Akande JO, Oloyede WT, Karem RA, et al. (2019) Comparison of serum level of anti-Mullerian hormone in fertile and infertile women in South West Nigeria. IJMDC 3:43-49. https://doi.org/10.24 911/IJMDC.51-1542882156

24. Mohammad MB, Seghinsara AM (2017) Polycystic ovary syndrome (PCOS), diagnostic criteria, and AMH. Asian Pac J Cancer Prev 18:17-21

25. Konishi S, Nishihama Y, lida A, Yoshinaga J, Imai H (2014) Association of Antimüllerian hormone levels with menstrual-cycle type and dysmenorrhea in young asymptomatic women. Fertil Steril 102:1439-1443. https://doi. org/10.1016/j.fertnstert.2014.07.1255

26. Streuli I, De Ziegler D, Gayet V, De Mouzon J, Santulli P, Chapron C (2012) In women with endometriosis anti-Müllerian hormone levels are decreased only in those with previous endometrioma surgery. Hum Reprod 27(11): 3294-3303. https://doi.org/10.1093/humrep/des274

27. Hvidman HW, Bentzen JG, Thuesen LL, Lauritsen MP, Forman JL, Loft A et al (2016) Infertile women below the age of 40 have similar anti-Müllerian hormone levels and antral follicle count compared with women of the same age with no history of infertility. Hum Reprod 31:1034-1045. https:// doi.org/10.1093/humrep/dew032

28. Shaw CM, Stanczyk FZ, Egleston BL, Kahle LL, Spittle CS, Godwin AK, Brinton LA, Dorgan JF (2011) Serum antimüllerian hormone in healthy premenopausal women. Fertil Steril 95:2718-2721

29. Kristensen SL, Ramlau-Hansen CH, Andersen CY, Ernst E, Olsen SF, Bonde JP et al (2012) The association between circulating levels of antimüllerian hormone and follicle number, androgens, and menstrual cycle characteristics in young women. Fertil Steril 97:779-785. https://doi.org/10.1 016/j.fertnstert.2011.12.017
30. Kallio S, Puurunen J, Ruokonen A, Vaskivuo T, Piltonen T, Tapanainen JS (2013) Antimüllerian hormone levels decrease in women using combined contraception independently of administration route. Fertil Steril 99:13051310. https://doi.org/10.1016/j.fertnstert.2012.11.034

31. Van den Berg MH, Dulmen-den V, Broeder E, Overbeek A, Twisk JWR, Schats E, van Leeuwen FE et al (2010) Comparison of ovarian function markers in users of hormonal contraceptives during the hormone-free interval and subsequent natural early follicular phases. Hum Reprod 25:1520-1527

\section{Publisher's Note}

Springer Nature remains neutral with regard to jurisdictional claims in published maps and institutional affiliations.

\section{Submit your manuscript to a SpringerOpen ${ }^{\circ}$ journal and benefit from:}

- Convenient online submission

- Rigorous peer review

- Open access: articles freely available online

- High visibility within the field

- Retaining the copyright to your article

Submit your next manuscript at $\boldsymbol{\nabla}$ springeropen.com 